\title{
Sliding mode control for performance improvement of shunt active power filter
}

\author{
Ikram Ullah ${ }^{1}$. Muhammad Ashraf ${ }^{1}$
}

(C) Springer Nature Switzerland AG 2019

\begin{abstract}
The increased use of non-linear loads results in more harmonics content in the source current. Shunt active power filters are used for correction of distorted source current by injecting a compensating current in parallel to the load current. The injected current will shape the supply current to a sinusoidal. In this paper an improved performance of shunt active power filter is achieved by using sliding mode controller for generation of gate pulses of voltage source inverter. The implemented control technique has been evaluated and compared with hysteresis current control. The performance parameters used for evaluating the shunt active power filter are total harmonic distortion, power factor and harmonics compensation ratio. The simulation results show excellent performance of active power filter in terms of harmonics mitigation and dynamic response. Experimental tests are also performed using NI DAQ card in Labview environment to validate the simulation results. Both the simulation and experimental results prove good performance of sliding mode control for accurate injection of reference current.
\end{abstract}

Keywords Harmonics mitigation · Shunt active power filter · Power quality improvement

\section{Introduction}

The technology advancement results in increased usage of electrical energy. The quality of power directly affects the performance efficiency of different electric apparatus. A distortion in the voltage waveform of the power source from a sine wave, or in the amplitude from a known reference level is considered as a power quality issue [1]. Voltage fluctuations, voltage sags, voltage unbalance, transients and harmonics are the well-known issues that affect the power quality [2].

Among the various power quality problems harmonics is considered as a major issue [3]. Harmonics in the power system are increasing rapidly due to the large scale use of power electronics equipment. The currents or voltages that are integer multiples of fundamental frequency are considered as harmonics [4]. The nonlinear loads connected to the supply are the main cause of harmonic currents.

The methods used for harmonics mitigation are K-rated transformers, separate neutral conductors, and harmonic filters [5]. Among all the techniques active power filters (APFs) are widely used for correction of distorted voltage or current waveforms. The concept of active power filters was first introduced by Gyugi and Strycula [6].

Due to significant growth in power electronics, the use of APF has unique advantages as compared to passive filter devices in harmonics mitigation [7]. In order to mitigate current harmonics the active power filter is connected in parallel with the load, this configuration is known as shunt active power filter (SAPF). The block diagram of SAPF connected to a three phase source driving a three phase non-linear load is shown in Fig. 1. The blocks included are reference current generator block, current injection controller block, dc link voltage control block and a voltage source inverter.

Ikram Ullah, ikramullah_73@yahoo.com | 'Department of Electrical Engineering, Capital University of Science and Technology (CUST), Islamabad, Pakistan.

SN Applied Sciences (2019) 1:531 | https://doi.org/10.1007/s42452-019-0554-9 


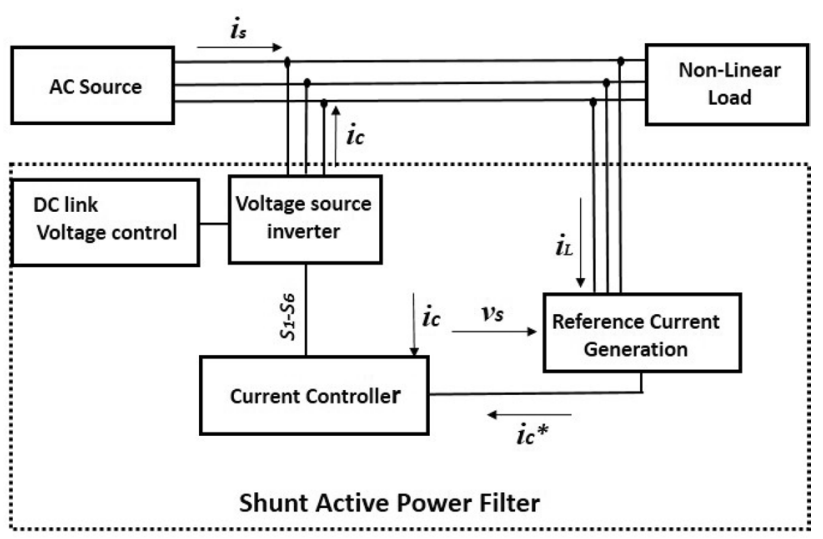

Fig. 1 Block diagram of SAPF

The procedure includes recognition of harmonic components, generation of reference current and gate pulses generation for the power circuit to inject the reference current. The power circuit consists of voltage source inverter with a DC link capacitor. In order to correct the distorted source current waveform the active power filter injects the reference current in parallel to the load thus cancelling out the current harmonics introduced by the nonlinear load. The reference current is actually anti-phase to the harmonic current, thus the injected current when added to the load current will make the source current very near to pure sinusoid. The supply current $\left(i_{s}\right)$ can be expressed as a difference of non-linear load current $\left(i_{l}\right)$ and compensating current $\left(i_{\mathrm{c}}\right)$ as shown in Eq. 1.

$i_{S}=i_{L}-i_{C}$

The performance evaluation parameters used in active power filtering are Total Harmonic Distortion (THD), power factor and harmonics compensation ratio (HCR). The total harmonic distortion (THD) for a current signal is defined as a measurement of the harmonic contents present by taking the ratio of addition of all the harmonic components of the current waveform $\left(I_{2}, I_{3}, I_{4} \ldots . I_{n}\right)$ to the fundamental component of the current waveform $\left(\mathrm{I}_{1}\right)[8]$ as shown in Eq. 2 below:

$\mathrm{THD}=\sqrt{\frac{l_{2}^{2}+l_{3}^{2}+l_{4}^{2}+\ldots l_{n}^{2}}{l_{1}^{2}}} 100 \%$

IEEE Std. 519 recommendations for harmonic control in power systems limits the THD of the source current to less than $5 \%$ [9]. The HCR factor [10] can be calculated as shown below:

$H C R=\frac{T H D \text { after compensation }}{T H D \text { before compensation }} \times 100 \%$
The methods used for reference current generation are established on either time domain techniques like Instantaneous Reactive Power ( $p-q)$ theory, Synchronous Reference Frame $(d-q)$ theory and perfect harmonic cancellation or frequency domain techniques like Discrete Fourier Transform (DFT) and sine multiplication method. The control of dc link voltage is also very important for accurate injection of the corrective current waveform at the point of common coupling (PCC) $[11,12]$. PI control or PID control is mostly used to regulate the dc link voltage. Different current controllers have been implemented to generate gate pulses for voltage source inverter [13-16]. In [13] the current injection is performed using deadbeat controller. The controller shows good dynamic response but is complex in implementation and has parameter dependence too. In $[17,18]$ the repetitive control method is introduced that shows good performance in terms of THD minimization but it is also supposed to have stability problems.

In $[17,18]$ the repetitive control method is introduced that shows good performance in terms of THD minimization but it is also supposed to have stability problems. In [19] One-cycle control (OCC) is implemented for current injection and showing good results in reducing THD, is robust and simple to implement. However, OCC controller is not stable for certain types of loads. In [20, 21] the conventional single band hysteresis current-control (SBHCC) scheme is used showing good accuracy and quick response, but the high switching frequency results in high switching losses. To overcome the problem of high switching frequency an adaptive hysteresis current-control [22] and double band hysteresis current control [23] are proposed.

In this paper sliding mode control is implemented to inject the reference current at the PCC. The implemented control technique results in good stability and reduced THD as compared to the conventional PWM control. Both simulation and experimental results verify the good performance of used control technique. This paper is organized such that Sect. 2 describes reference current generation technique. In Sect. 3 mathematical model of SAPF is discussed and in Sect. 4 current injection control is explained. Detailed results are given in Sect. 5. Section 6 concludes the paper.

\section{Reference current generation}

One of the main contribution in active power filtering is generating a reference current which is actually $180^{\circ}$ out of phase with the harmonics current. The addition of reference current to the load current results in sinusoidal source current. Many techniques are used for reference current generation but in this paper Instantaneous 
Reactive Power theory ( $p$-q theory) is used due to its simplicity and accuracy.

\subsection{Instantaneous reactive power theory}

This theory is mostly used for reference current generation in active power filters. In this theory variable transformation is used to transform the co-ordinates from $a$ $b$-c reference frame to the $\alpha-\beta-0$ reference frame [24]. The instantaneous three phase voltages and currents are used as input for doing the co-ordinate transformation [25] as shown in Eqs. 4 and 5.

$$
\begin{aligned}
& {\left[\begin{array}{l}
v_{0} \\
v_{\alpha} \\
v_{\beta}
\end{array}\right]=\sqrt{\frac{2}{3}}\left[\begin{array}{ccc}
1 / \sqrt{2} & 1 / \sqrt{2} & 1 / \sqrt{2} \\
1 & -1 / 2 & 1 / 2 \\
0 & \sqrt{3} / 2 & -\sqrt{3} / 2
\end{array}\right]\left[\begin{array}{l}
v_{s a} \\
v_{s b} \\
v_{s c}
\end{array}\right]} \\
& {\left[\begin{array}{c}
i_{0} \\
i_{\alpha} \\
i_{\beta}
\end{array}\right]=\sqrt{\frac{2}{3}}\left[\begin{array}{ccc}
1 / \sqrt{2} & 1 / \sqrt{2} & 1 / \sqrt{2} \\
1 & -1 / 2 & 1 / 2 \\
0 & \sqrt{3} / 2 & -\sqrt{3} / 2
\end{array}\right]\left[\begin{array}{l}
i_{s a} \\
i_{s b} \\
i_{s c}
\end{array}\right]}
\end{aligned}
$$

The source currents and phase neutral voltages are used to derive the instantaneous real and imaginary power components as given in Eq. 6 .

$$
\left[\begin{array}{c}
p_{0} \\
p \\
q
\end{array}\right]=\left[\begin{array}{ccc}
v_{0} & 0 & 0 \\
0 & v_{\alpha} & v_{\beta} \\
0 & -v_{\beta} & v_{\alpha}
\end{array}\right]\left[\begin{array}{c}
i_{0} \\
i_{\alpha} \\
i_{\beta}
\end{array}\right]
$$

The zero sequence power only exists in three phase systems with a neutral wire. As the system considered in this paper is three phase three wire, the zero sequence power and current are ignored.

$\left[\begin{array}{l}p \\ q\end{array}\right]=\left[\begin{array}{cc}v_{\alpha} & v_{\beta} \\ -v_{\beta} & v_{\alpha}\end{array}\right]\left[\begin{array}{l}i_{\alpha} \\ i_{\beta}\end{array}\right]$

This active and reactive power can be expressed in two parts i.e. $A C$ and $D C$ as given by Eq. 8 .

$\left.\begin{array}{l}p=\tilde{p}+\bar{p} \\ q=\tilde{q}+\bar{q}\end{array}\right\}$

A low pass filter is used to get the $D C$ part of active and reactive power by passing $p$ and $q$ signal through it. The high frequency component will be filtered out and leaving the expected signal i.e. Fundamental part. In the next step the reference current in $\alpha-\beta$ co-ordinates is calculated by Eq. 9 .

$$
\left[\begin{array}{c}
i_{\alpha}^{*} \\
i_{\beta}^{*}
\end{array}\right]=\frac{1}{v_{\alpha} 2+v_{\beta} 2}\left[\begin{array}{cc}
v_{\alpha} & -v_{\beta} \\
v_{\beta} & v_{\alpha}
\end{array}\right] *\left[\begin{array}{c}
\bar{p} \\
\bar{q}
\end{array}\right]
$$

In the final step the reference current in $a-b$-c co-ordinates is calculated by using Eq. 10 .

$$
\left[\begin{array}{l}
i_{c a}^{*} \\
i_{c b}^{*} \\
i_{c c}^{*}
\end{array}\right]=\sqrt{\frac{2}{3}}\left[\begin{array}{ccc}
1 & 0 & 1 / \sqrt{2} \\
-1 / 2 & \sqrt{3} / 2 & 1 / \sqrt{2} \\
-1 / 2 & -\sqrt{3} / 2 & 1 / \sqrt{2}
\end{array}\right] *\left[\begin{array}{c}
i_{0}^{*} \\
i_{\alpha}^{*} \\
i_{\beta}^{*}
\end{array}\right]
$$

\section{Mathematical model of SAPF}

The three phase source with active filter connected in parallel to the distribution load is analyzed by building a mathematical model of SAPF. The basic structure of three phase SAPF in parallel to a non-linear load is shown in Fig. 2. The source voltage $v_{s}$ is supposed pure sinusoidal. It is modeled in the stationary a-b-c reference frame using Eq. 11.

$\left\{\begin{array}{l}L \frac{d}{d t} i_{c a}=v_{s a}-R i_{c a}-v_{a} \\ L \frac{d}{d t} i_{c b}=v_{s b}-R i_{c b}-v_{b} \\ L \frac{d}{d t} i_{c c}=v_{s c}-R i_{c c}-v_{c} \\ C_{d c} \frac{d}{d t} v_{d c}=f_{a} i_{c a}+f_{b} i_{c b}+f_{c} i_{c c}\end{array}\right\}$

where $f_{a}, f_{b}$, and $f_{c}$ are switching functions. $L c$ and $R c$ are filter inductance and its resistance, respectively. $C_{d c}$ is the capacitance at the DC link. The above Equation can be written in matrix form as:

$\frac{d}{d t}\left[\begin{array}{c}i_{c a} \\ i_{c b} \\ i_{c c} \\ v_{d c}\end{array}\right]=\left[\begin{array}{cccc}-\frac{R}{L} & 0 & 0 & 0 \\ 0 & -\frac{R}{L} & 0 & 0 \\ 0 & 0 & -\frac{R}{L} & 0 \\ \frac{f_{a}}{c_{d c}} & \frac{f_{b}}{c_{d c}} & \frac{f_{c}}{c_{d c}} & 0\end{array}\right]\left[\begin{array}{c}i_{c a} \\ i_{c b} \\ i_{c c} \\ v_{d c}\end{array}\right]+\frac{1}{L}\left[\begin{array}{c}v_{s a}-v_{a} \\ v_{s b}-v_{b} \\ v_{s c}-v_{c} \\ 0\end{array}\right]$

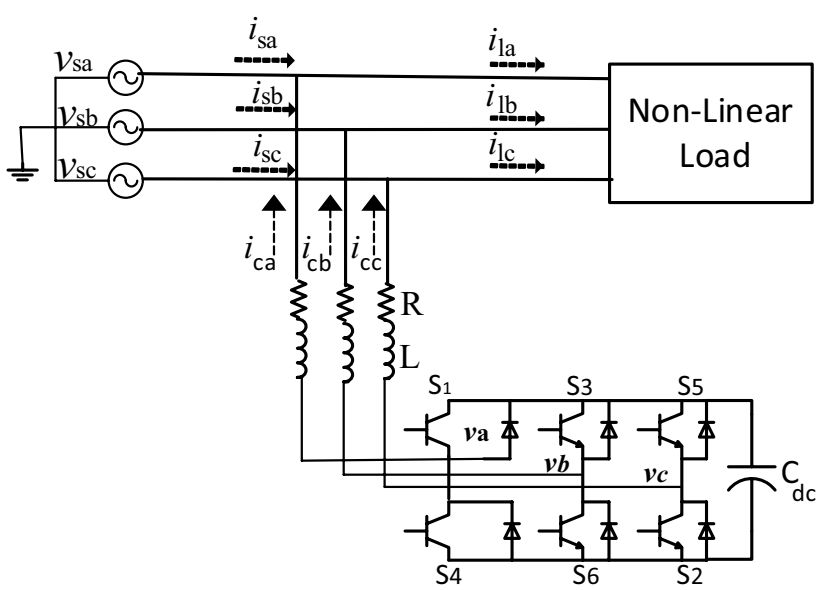

Fig. 2 Basic structure of SAPF 
The stationary a-b-c reference frame model of the active power filter can be converted to the rotating $d$-q reference frame in order to reduce control complexity. The transformation matrix required for conversion from $a-b-c$ to an arbitrary rotating $\mathrm{d}-\mathrm{q}-0$ reference frame is given below:

$T=\frac{2}{3}\left[\begin{array}{ccc}\cos \theta & \cos \left(\theta-\frac{2 \pi}{3}\right) & \cos \left(\theta+\frac{2 \pi}{3}\right) \\ \sin \theta & \sin \left(\theta-\frac{2 \pi}{3}\right) & \sin \left(\theta+\frac{2 \pi}{3}\right) \\ \frac{1}{2} & \frac{1}{2} & \frac{1}{2}\end{array}\right]$

For simplicity a balance three-phase system without a neutral line is considered for which the sum of the instantaneous three-phase voltages and currents is zero as shown in Eq. 14.

$i_{s a}+i_{s b}+i_{s c}=0$

$\left.v_{s a}+v_{s b}+v_{s c}=0\right\}$

The dynamical model of the system in $\mathrm{d}$-q-0 reference frame results in Eq. 15.

$\frac{d}{d t}\left[\begin{array}{c}i_{c d} \\ i_{c q} \\ v_{d c}\end{array}\right]=\left[\begin{array}{ccc}-\frac{R}{L} & \omega & -\frac{f_{d}}{f^{\prime}} \\ -\omega & -\frac{R}{L} & -\frac{f_{q}}{L} \\ \frac{f_{d}}{c_{d c}} & \frac{f_{q}}{c_{d c}} & 0\end{array}\right]\left[\begin{array}{c}i_{c d} \\ i_{c q} \\ v_{d c}\end{array}\right]+\frac{1}{L_{c}}\left[\begin{array}{c}v_{d} \\ v_{q} \\ 0\end{array}\right]$

where the switching state functions of the system in $d-q$ reference frame are denoted by $f_{d}$ and $f_{q}$ and $\omega$ is the supply angular frequency. Equation 16 is shown as:

$\left\{\begin{array}{l}L \frac{d}{d t} i_{c d}=v_{d}-R i_{c d}+\omega L i_{c q}-f_{d} \cdot v_{d c} \\ L \frac{d}{d t} i_{c q}=v_{q}-R i_{c q}-\omega L i_{c d}-f_{q} \cdot v_{d c} \\ C_{d c} \frac{d}{d t} v_{d c}=f_{d} i_{c d}+f_{q} i_{c q}\end{array}\right\}$

\section{Current injection}

The injection of reference current in parallel to the load must be done accurately so as to make the source current sinusoidal. Different controllers are used for current injection. In [26] a comparison is made between hysteresis current control and sinusoidal pulse width modulation techniques. In [27] a new current control scheme was proposed for selective harmonic compensation. The proposed work used an array of resonant current controllers achieved good results in terms of THD reduction. Many researchers employed different controllers for current injection [28-36] including model predictive control, repetitive control, kalman filter based $\mathrm{H}$ infinity control strategy, one cycle control and sliding mode control. Current controllers force the actual compensating current to follow the reference current and hence the performance of SAPF is significantly affected by current controller's selection.

\subsection{Sliding mode control}

Sliding mode control is a nonlinear control method which changes the dynamics of a nonlinear system by application of a discontinuous control. Since the APF system is a nonlinear system and the control of APF is completely based on control of the switches, SMC method is known to be a best method to produce switching signals for voltage source inverter by applying it to bring the system's state trajectory on to a user defined surface called sliding surface and to maintain the trajectory on that surface for the rest of the time [37]. The design methodology of sliding mode control for shunt active power filter is outlined in this section.

The sliding mode control is the motion of state variables under the sliding surface. The state variables of the system can converge to the equilibrium point in steady state condition. After the creation of sliding surface the trajectories are enforced to reach sliding surface in finite time and stay there for the rest of the time. After reaching the sliding surface the system dynamics are unaffected by circuit parameters and only depend on the selected sliding surface.

SMC can be designed basically in two steps. In first step a suitable sliding surface is designed and in the second step a control law is designed to force the system trajectories to reach the sliding surface and stay there. For the active power filter, modulating signal $U$ is considered as the control input. While designing the sliding mode controller, control input can be composed of two components, a continuous component $U_{\text {eq }}$ and the discontinuous one $U_{\mathrm{n}}$ as shown in Eq. 17.

$U=U_{e q}+U_{n}$

The discontinuous component brings the system on sliding surface and once the system reaches the sliding surface, the continuous component ensures the system to be there. In $\mathrm{d}$-q frame the control can be expressed by Eq. 18 .

$U_{d q}=U_{e q, d q}+U_{n, d q}$

where

$U_{d q}=\left\{\begin{array}{l}U_{d} \\ U_{q}\end{array}\right\}, \quad U_{e q, d q}=\left\{\begin{array}{l}U_{e q, d} \\ U_{e q, q}\end{array}\right\} \quad$ and $\quad U_{n, d q}=\left\{\begin{array}{l}U_{n, d} \\ U_{n, q}^{\prime}\end{array}\right\}$

\subsubsection{Sliding surface design}

In general form the sliding surface can be written as:

$S=K\left(x-x^{*}\right)$ 
where $x=\left[\begin{array}{l}x_{1} \\ x_{2} \\ x_{3}\end{array}\right]=\left[\begin{array}{c}i_{c d} \\ i_{c q} \\ v_{d c}\end{array}\right], x^{*}=\left[\begin{array}{c}x_{1}^{*} \\ x_{2}^{*} \\ x_{3}^{*}\end{array}\right]=\left[\begin{array}{c}i_{c d}^{*} \\ i_{c q}^{*} \\ v_{d c}^{*}\end{array}\right]$ and $K=$
$\left[\begin{array}{ccc}k_{i c} & 0 & k_{v d} \\ 0 & k_{i c} & k_{v q}\end{array}\right]$

The sliding surface on $\mathrm{d}$-q frame is given by Eq. 20 while $U_{\text {nd }}$ and $U_{\text {nq }}$ are given by Eq. 21 .

$S=\left[\begin{array}{l}S_{d} \\ S_{q}\end{array}\right]=\left[\begin{array}{l}k_{i c}\left(i_{c d}-i_{c d}^{*}\right)+k_{v d}\left(v_{d c}-v_{d c}^{*}\right) \\ k_{i c}\left(i_{c q}-i_{c q}^{*}\right)+k_{v q}\left(v_{d c}-v_{d c}^{*}\right)\end{array}\right]$

$U n, d= \begin{cases}-\operatorname{sgn}\left(S_{d}\right), & S_{d} \neq 0 \\ 0, & S_{d}=0\end{cases}$

Un, $q= \begin{cases}-\operatorname{sgn}\left(S_{q}\right), & S_{q} \neq 0 \\ 0, & S_{q}=0\end{cases}$

The mathematical model described in Sect. 3 is used to derive the equivalent control on $\mathrm{d}$-q frame. The state variable model of SAPF can be written in general form as:

$x=A x+B(x) u+G$

where $A, B$ and $G$ are obtained as shown in Eq. 23.

$\frac{d}{d t}\left[\begin{array}{l}i_{c d} \\ i_{c q} \\ v_{d c}\end{array}\right]=\left[\begin{array}{ccc}-\frac{R}{L} & w & 0 \\ -\omega & -\frac{R}{L} & 0 \\ 0 & 0 & 0\end{array}\right]\left[\begin{array}{l}i_{c d} \\ i_{c q} \\ v_{d c}\end{array}\right]+\left[\begin{array}{cc}\frac{v_{d c}}{L} & 0 \\ 0 & \frac{v_{d c}}{L} \\ -\frac{i_{c d}}{C_{d c}} & \frac{i_{i_{c q}}}{C_{d c}}\end{array}\right]\left[\begin{array}{l}f_{d} \\ f_{q}\end{array}\right]+\left[\begin{array}{c}-\frac{v_{d}}{L} \\ 0 \\ 0 \\ \lceil G\rceil\end{array}\right]$

The equivalent control can be found by setting the derivative of the sliding surface to zero and substituting $U=U_{\text {eq }}$.

$\dot{S}=K\left(\dot{x}-\dot{x}^{*}\right)=0$

$0=K\left(A x+B(x) U_{e q}+G\right)-K \dot{x}^{*}$

$\left.\begin{array}{l}(K B(x))^{-1} \cdot K\left(\dot{x}^{*}-A x-G\right)=(K B(x))^{-1} \cdot K B(x) U_{e q} \\ U_{e q}=(K B(x))^{-1} \cdot K\left(x^{*}-A x-G\right)\end{array}\right\}$

\subsubsection{Stability analysis}

The stability analyses are performed to ensure that the system trajectory reaches the equilibrium point and settles there for the rest of the time. The system trajectory for a stable system should slide along the surface and finally settle at the equilibrium point. In case of an unstable system the trajectory does not settle at the equilibrium point but crosses it and moves toward infinity. In this section the system stability using the sliding mode controller is analysed by adopting a Lyapunov function as a candidate function i.e.

$V=\frac{1}{2} S^{2}$
The time derivative of Eq. 25 is written as:

$\dot{V}=S \dot{S}$

In general the condition of the sliding mode controller is defined by Eq. 27 .

$\dot{V}=S \dot{S}<0$

The time derivative of Eq. 19 results in

$\dot{S}=K\left(A x+B(x)\left(U_{e q, d q}-\operatorname{sgn}\left(S_{d q}\right)\right)+G-\dot{x}^{*}\right)$

Assuming zero initial values and neglecting the external disturbances Eq. 28 can be written as:

$\dot{S}=K B(x) \cdot(-\operatorname{sgn}(s))$

The condition for selecting the sliding mode gains can be obtained by putting Eqs. 20 and 29 into 27 as shown below:

$\frac{L}{C_{d c}} \cdot\left(k_{v d}+k_{v q}\right) \cdot\left(\left|i_{c d}\right|+\left|i_{c q}\right|\right)<k_{i c} v_{d c}$

\subsection{Hysteresis current control}

In hysteresis current controller the switching pulses of inverter are generated by setting a fixed hysteresis band and comparing it with a current error signal [30]. Whenever the injected current exceeds the upper or lower limit, the hysteresis controller generates the switching pulses of IGBT. This technique has the advantages of simplicity, good accuracy, robustness and fast dynamic response. The tracking of reference current is done by limiting the actual current within the set band. When the actual current increases than the upper limit of the hysteresis band $(\mathrm{HB})$, it should be reduced. This is done by turning ON of the lower switch of the inverter arm and turning OFF the upper switch, thus the current starts falling. Similarly when the actual current exceeds the lower boundary of the band, the upper switch is turned ON, and the lower switch is turned OFF, thus the current starts rising. Consequently, the current is retained within the hysteresis band. Therefore, the actual current is forced to track the reference current in the hysteresis band.

\section{Results}

\subsection{Simulation results}

The Shunt active power filter has been simulated twice for each test case, first by injecting current using sliding mode control and second time by using hysteresis current control. For the purpose of simulation a three phase three 
Table 1 Source parameters

\begin{tabular}{|c|c|c|c|c|c|c|c|c|c|}
\hline \multirow{3}{*}{$\begin{array}{l}\text { Elements } \\
\text { Parameter }\end{array}$} & \multicolumn{2}{|l|}{ AC Source } & \multicolumn{3}{|l|}{ SAPF } & \multicolumn{4}{|c|}{ Non-linear load } \\
\hline & \multirow{2}{*}{$\begin{array}{l}\text { RMS line-line } \\
\text { supply volt- } \\
\text { age }\end{array}$} & \multirow{2}{*}{$\begin{array}{l}\text { Supply } \\
\text { frequency }\end{array}$} & \multirow{2}{*}{$\begin{array}{l}\text { Dc link volt- } \\
\text { age reference }\end{array}$} & \multirow{2}{*}{$\begin{array}{l}\text { Dc link } \\
\text { capacitor }\end{array}$} & \multirow{2}{*}{$\begin{array}{l}\text { Filter induct- } \\
\text { ance }\end{array}$} & \multirow{2}{*}{$\begin{array}{l}\text { 3-phase } \\
\text { diode recti- } \\
\text { fier }\end{array}$} & \multicolumn{3}{|c|}{ Load impedance } \\
\hline & & & & & & & Case 1 & Case 2 & Case 3 \\
\hline Value & $380 \mathrm{~V}$ & $50 \mathrm{~Hz}$ & $800 \mathrm{~V}$ & $2200 \mu \mathrm{F}$ & $2 \mathrm{mH}$ & - & $10 \Omega$ & $10 \Omega, 100 \mu \mathrm{F}$ & $\begin{array}{l}10 \Omega, 100 \mu \mathrm{F} \\
18 \mathrm{mH}\end{array}$ \\
\hline
\end{tabular}

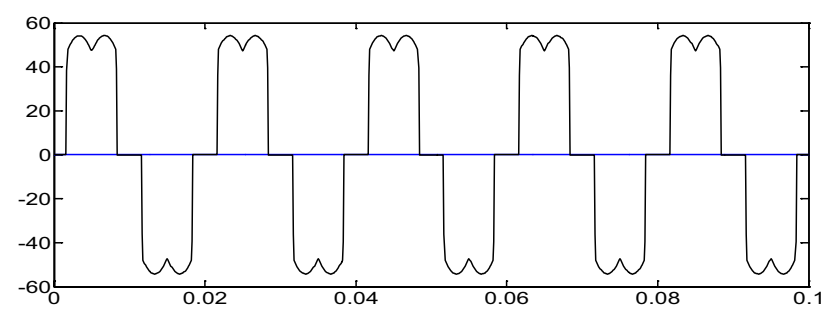

Fig. 3 Distorted source current waveform for case 1

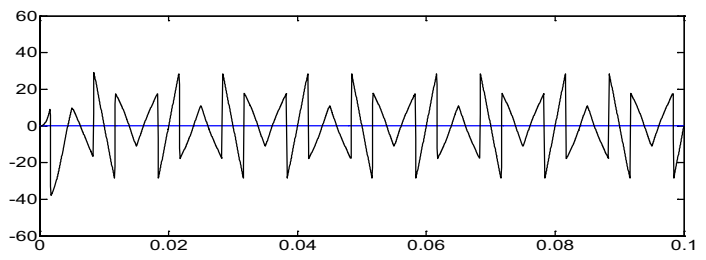

Fig. 4 Reference current waveform for case 1

wire system with balanced load has been considered. The parameters used for simulation are shown in Table 1.

The performance of the SAPF is analyzed by calculating the THD of the source current, power factor and HCR. The model is simulated for three different loads. These cases are discussed separately.

\section{Case 1: Resistive load}

In this case a resistor is connected across a three phase bridge rectifier and its current waveform is shown in Fig. 3. The reference current generated in this case is shown in Fig. 4. THD of the source current without active power filter is $29.02 \%$ and with active power filter using sliding mode control, THD has been reduced to $1.45 \%$ as shown in Fig. 5 . The circuit is again simulated by using hysteresis current control technique for current injection thus reducing THD to $2.28 \%$ as shown in Fig. 6.

\section{Case 2: RC load}

For case 2 a capacitor is connected in parallel with the resistor as shown in Fig. 7 and THD of the source current

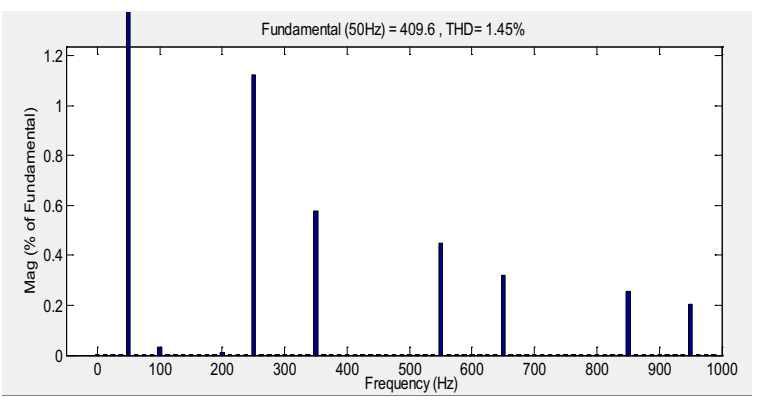

Fig. 5 THD using SMC

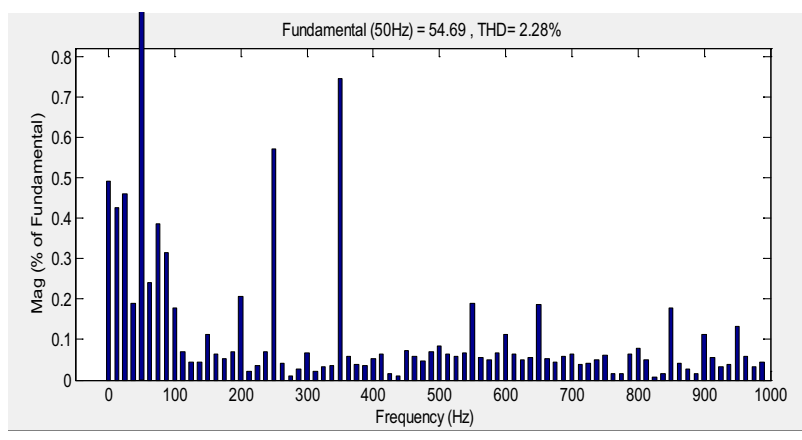

Fig. 6 THD using HCC

without SAPF is noted as $31.53 \%$. The distorted source current waveform in this case is shown in Fig. 8 and reference current waveform is shown in Fig. 9. Injection of reference current is done again with both SMS and HCC and THD results for the compensated source current waveform are shown in Figs. 10 and 11.

\section{Case 3: RLCload}

In case $3 \mathrm{RLC}$ load is connected to analyze the current control technique. THD of the distorted source current waveform is found to be $35.33 \%$. The distorted source current waveform is shown in Figs. 12 and 13 shows the reference current. The complete model is again simulated with the two techniques for current injection and the resultant 


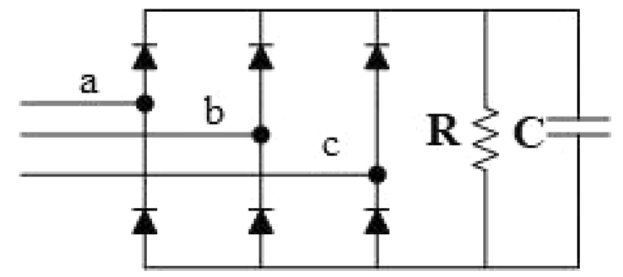

Fig. 7 Non-linear Load

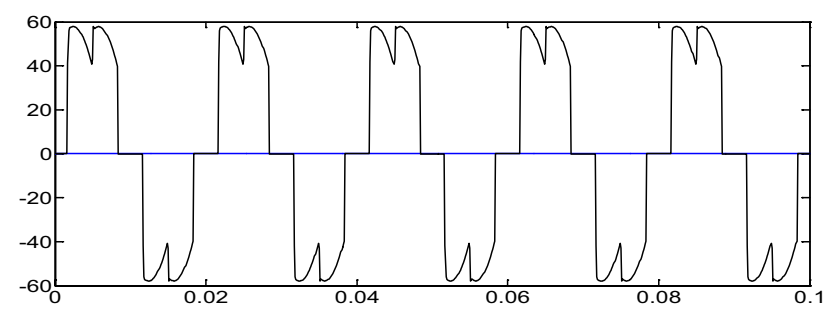

Fig. 8 Distorted source current waveform for case 2

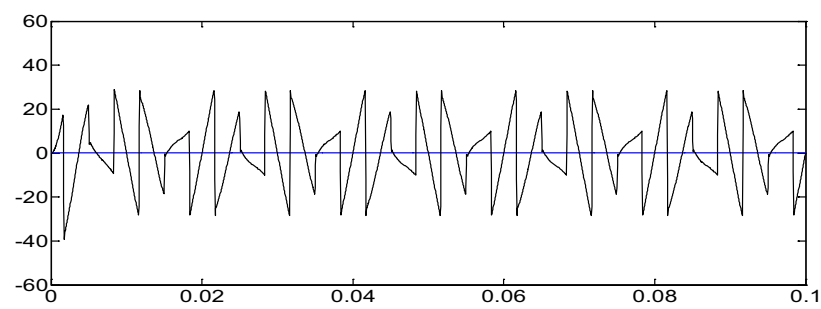

Fig. 9 Reference current waveform for case 2

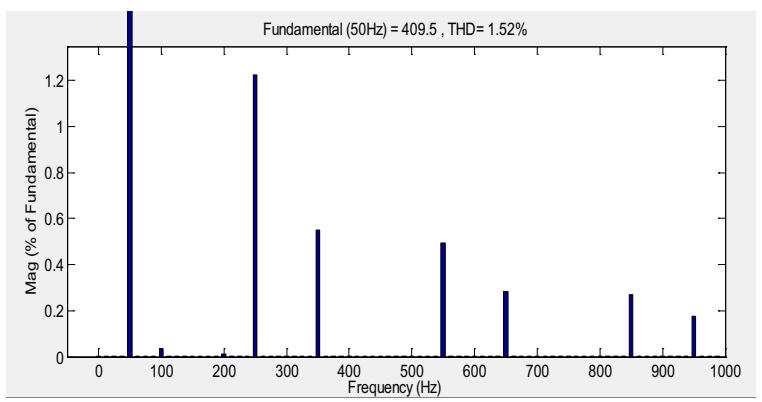

Fig. 10 THD using SMC

THD of the compensated source current for both cases is shown in Figs. 14 and 15.

The THD results for all the three cases are shown in Figs. $5 \& 6,9 \& 10$ and $13 \& 14$. It is observed that by using sliding mode control for current injection source current THD is reduced to a lower value as compared to hysteresis current control. This proves the good performance of sliding mode control in accurately tracking the reference

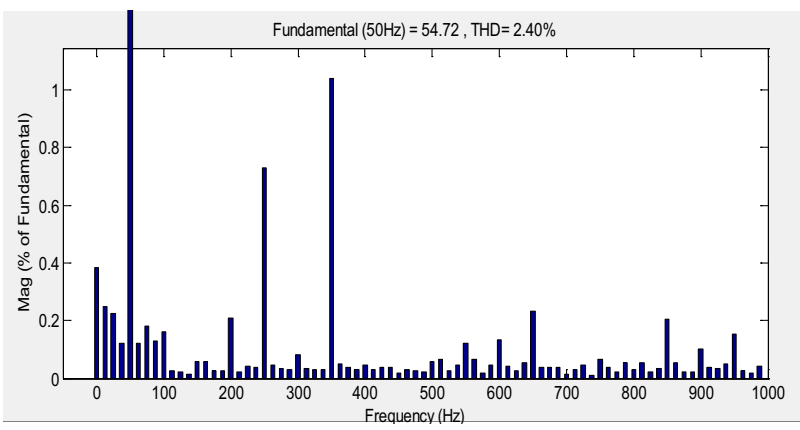

Fig. 11 THD using HCC

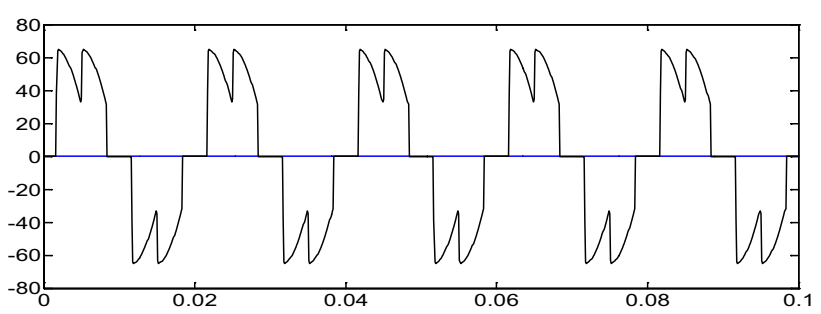

Fig. 12 Distorted source current waveform for case 3

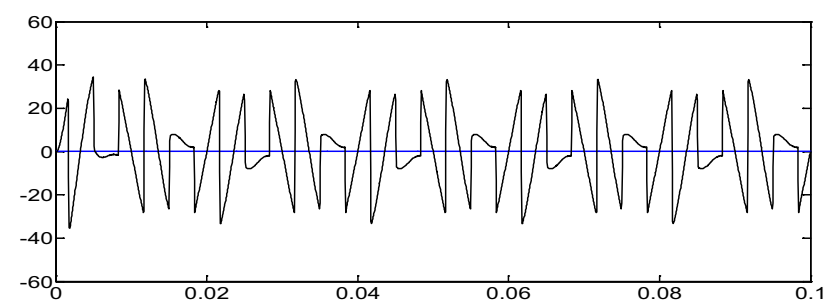

Fig. 13 Reference current waveform for case 3

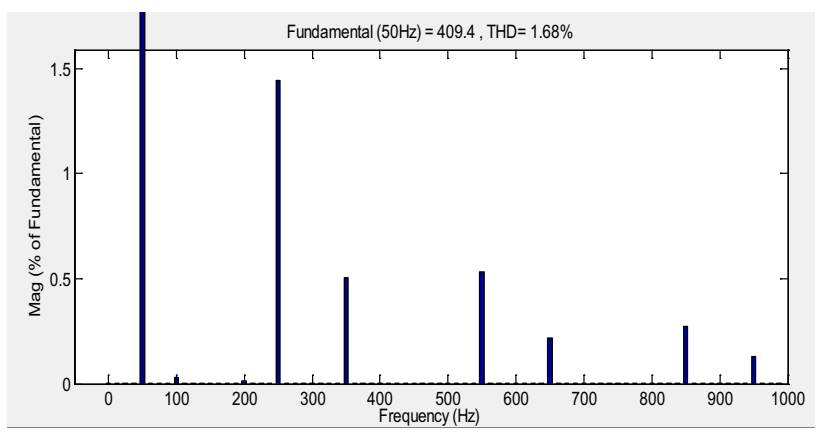

Fig. 14 THD using SMC

current. Moreover the HCR factor only changes slightly due to change in load thus proving good stability. The summary of results is shown in Table 2. 


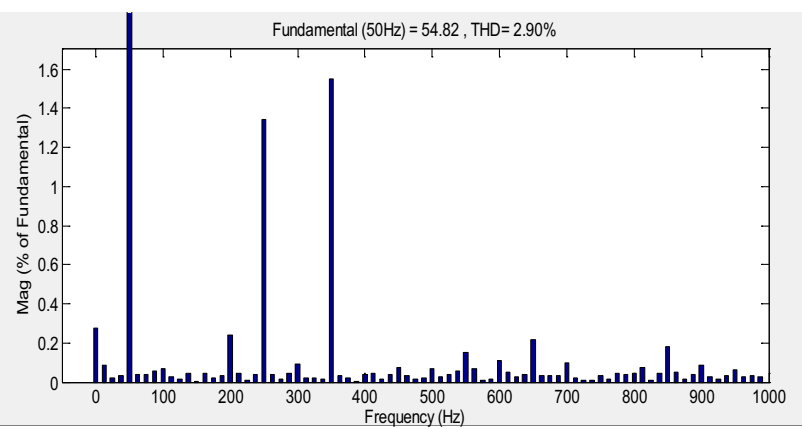

Fig. 15 THD using HCC

\subsection{Experimental results}

The simulation results are verified experimentally in a labview environment. The NI DAQ (USB6002) board is used for data acquisition. Signal conditiong module is used for interfacing the voltage and current signals at the analogue input of DAQ board. The labview software reads the distorted source current waveform and generates the reference current waveform. The reference current generated is sent to the current controller to generate gate pulses for VSI. Three different loads are used to evaluate the sliding mode control technique. The experimental setup is shown in Fig. 16. Figures 17, 18 and 19 shows the load current, reference current and source current after compensation for case 1. Similarly Figs. 20, 21, 22 and Figs. 23, 24, 25 shows results for case 2 and case 3 respectively. These results validates the simulation results.

\section{Conclusion}

In this paper an improved performance of shunt active power filter is achieved by using sliding mode control for generating gate pulses of voltage source inverter. A threephase three-wire system with a balanced non-linear load is used. The performance of the sliding mode control is

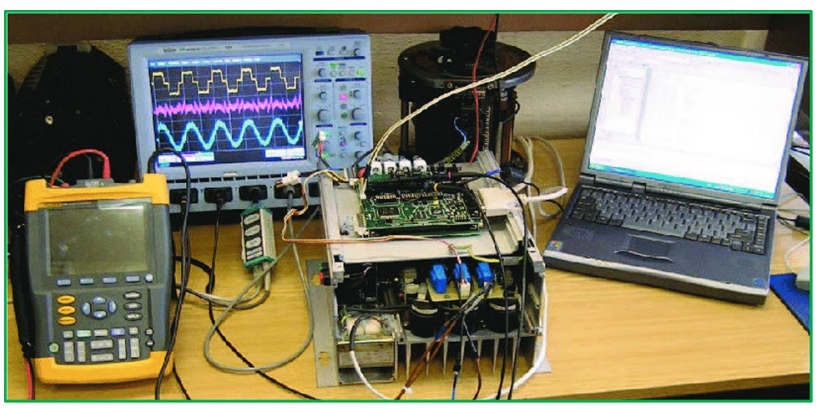

Fig. 16 Experimental setup

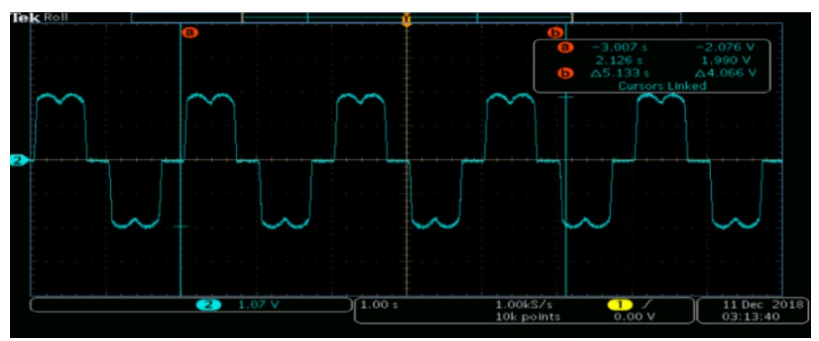

Fig. 17 Load current (case 1)

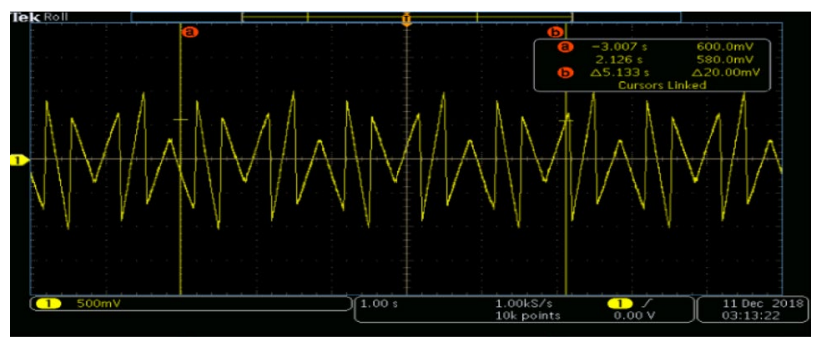

Fig. 18 Reference current (case 1)

analyzed by comparing it with the hysteresis current control technique. The parameters used for performance evaluation are THD, power factor and HCR. The results show that by using SMC, SAPF is able to mitigate harmonics with
Table 2 Performance parameters

\begin{tabular}{|c|c|c|c|c|c|c|c|}
\hline \multirow[t]{2}{*}{ Load } & \multirow[t]{2}{*}{$\begin{array}{l}\text { THD before compen- } \\
\text { sation (\%) }\end{array}$} & \multicolumn{2}{|c|}{$\begin{array}{l}\text { THD after compensa- } \\
\text { tion (\%) }\end{array}$} & \multicolumn{2}{|c|}{ Power factor } & \multicolumn{2}{|c|}{ HCR (\%) } \\
\hline & & SMC & $\mathrm{HCC}$ & SMC & $\mathrm{HCC}$ & SMC & $\mathrm{HCC}$ \\
\hline Case 1 & 29.02 & 1.45 & 2.28 & 0.998 & 0.988 & 4.99 & 7.85 \\
\hline Case 2 & 31.53 & 1.52 & 2.40 & 0.991 & 0.981 & 4.82 & 7.61 \\
\hline Case 3 & 35.33 & 1.68 & 2.90 & 0.980 & 0.975 & 4.75 & 8.21 \\
\hline
\end{tabular}




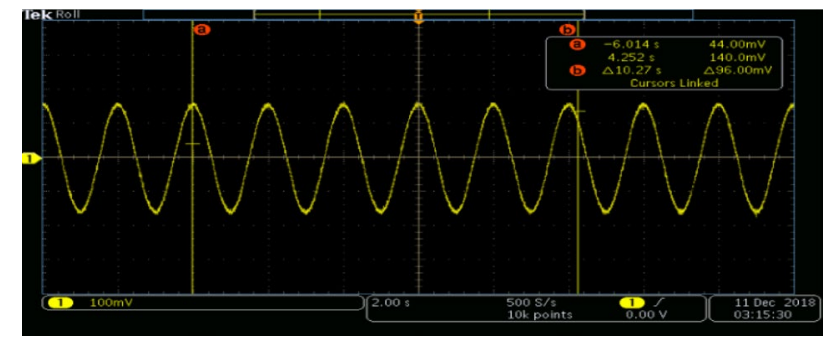

Fig. 19 Compensated source current (case 1)

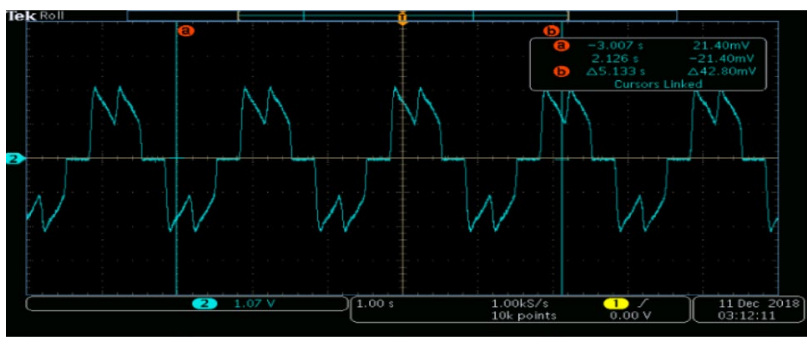

Fig. 20 Load current (case 2)

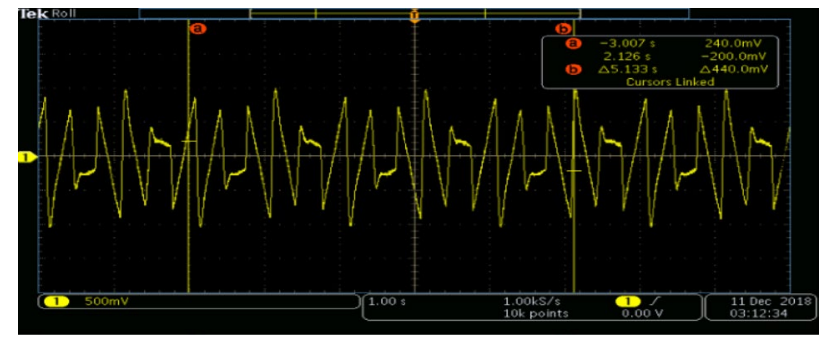

Fig. 21 Reference current (case 2)

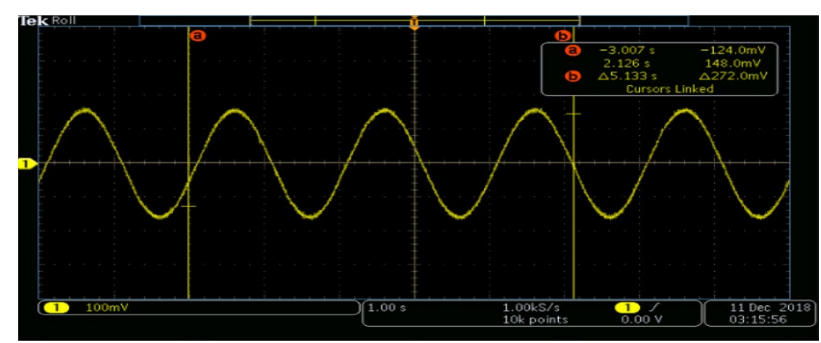

Fig. 22 Compensated source current (case 2)

good accuracy and THD of the source current is reduced to a lower value as compared to HCC. The power factor has been significantly improved using sliding mode control. The HCR factor in case of SMC also changes by only a small margin as compared to HCC for three different loads ensuring good stability against a change in load.

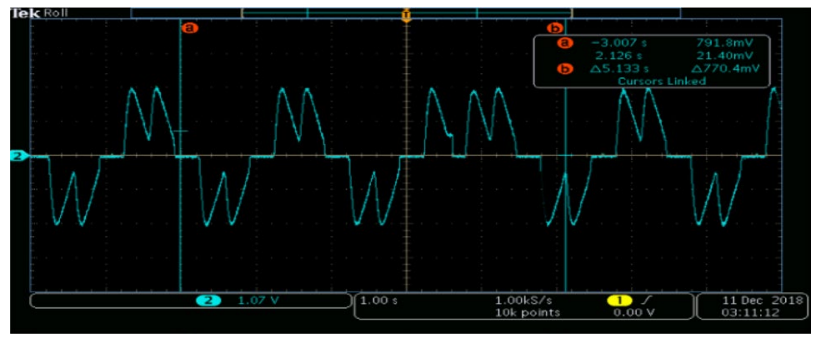

Fig. 23 Load current (case 3)

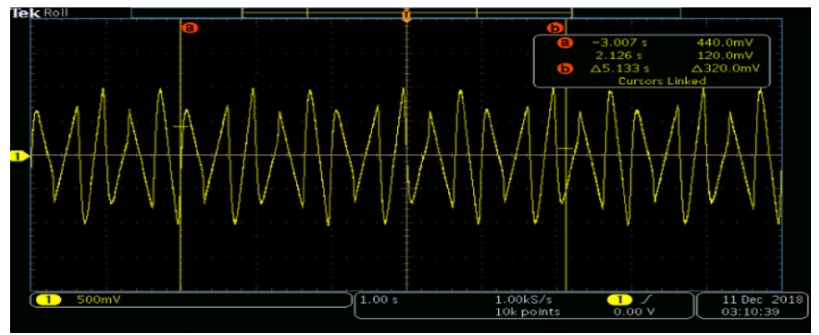

Fig. 24 Reference current (case 3)

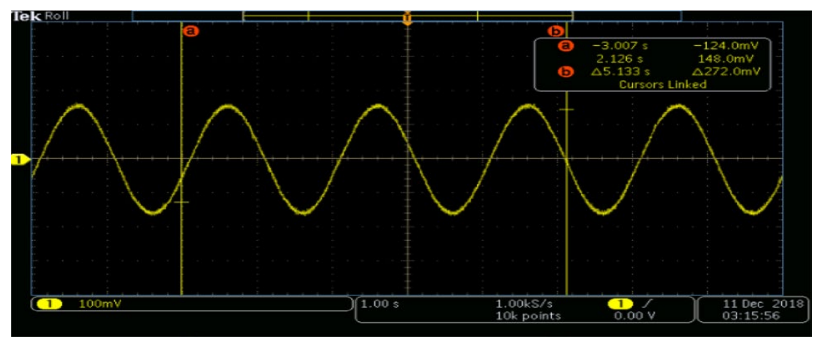

Fig. 25 Compensated source current (case 3)

\section{Compliance with ethical standards}

Conflict of interest On behalf of all authors, I being the corresponding author states that there is no conflict of interest.

\section{References}

1. Singh B et al (1999) A review of active filters for power quality improvement. IEEE Trans Ind Electron 46(5):960-971

2. Moravek J et al (2016) Power quality issues related to power flow control in systems with renewable energy micro sources. In: 2016 17th international scientific conference on electric power engineering (EPE). IEEE, pp 1-6

3. Pandey $S$ et al (2016) Harmonic mitigation techniques in modern power system: a review. Global J Multidiscip Stud 5(9):1573-1580

4. Pejovic $P$ (2007) Three-phase diode rectifiers with low harmonics. Springer, Berlin 
5. Khadkikar V (2012) Enhancing electric power quality using UPQC: a comprehensive overview. IEEE Trans Power Electron 27(5):2284-2297

6. Gyugyi L, Strycula EC (1976) Active ac power filters. In: Proceedings of IEEE/IAS annual meeting, pp 81-87

7. Singh B et al (1998) A universal active power filter for singlephase reactive power and harmonic compensation. In: Power quality. IEEE

8. Abdikarimuly R (2016) Calculation of current total harmonic distortion for a single-phase multilevel inverter with LCL-filter. In: 2016 IEEE international power electronics and motion control conference (PEMC)

9. 519-2014-IEEE recommended practice and requirements for harmonic control in electric power systems

10. Panigrahi $R$ et al (2016) A robust LQG servo control strategy of shunt-active power filter for power quality enhancement. IEEE Trans Power Electron 31(4):2860-2869

11. Choi W-H et al (2013) Analysis of dc-link voltage controls in three-phase four-wire hybrid active power filters. IEEE Trans Power Electron 28(5):2180-2191

12. Wang $Y$ et al (2015) The influence of DC-link voltage control on the performance of active power filter. In: 2015 IEEE applied power electronics conference and exposition (APEC). IEEE

13. Kim B-J (2015) An improved deadbeat control method based on current predictive algorithm for shunt active power filter. In: 2015 IEEE 2nd international future energy electronics conference (IFEEC)

14. Ruanmakok K (2014)The control of shunt active power filter using sliding mode controller. In: 2014 11th international conference on electrical engineering/electronics, computer, telecommunications and information technology (ECTI-CON)

15. Morales J et al (2018) Modeling and sliding mode control for three-phase active power filters using the vector operation technique. IEEE Trans Ind Electron 65(9):6828-6838

16. Cao D et al (2016) Adaptive fractional fuzzy sliding mode control for three-phase active power filter. IEEE Access 4:6645-6651

17. Garcia-Cerrada A et al (2007) Application of a repetitive controller for a three-phase active power filter. IEEE Trans Power Electron 22(1):237-246

18. Xie $C$ et al (2017) Multirate fractional-order repetitive control of shunt active power filter suitable for microgrid applications. IEEE J Emerg Sel Top Power Electron 5(2):809-819

19. Bento AA et al (2017) Fast response one-cycle control strategy for three-phase shunt active power filter. In: 2017 IEEE southern power electronics conference (SPEC). IEEE

20. Durna E (2018) Adaptive fuzzy hysteresis band current control for reducing switching losses of hybrid active power filter. IET Power Electron 11(5):937-944

21. Mao H, Yang X, Chen Z, Wang Z (2012) A hysteresis current controller for single-phase three-level voltage source inverters. IEEE Trans Power Electron 27(7):3330-3339

22. Adam $\mathrm{G}$ et al (2012) An adaptive hysteresis band current control for three phase shunt active power filter using fuzzy logic. In: 2012 international conference and exposition on electrical and power engineering (EPE). IEEE
23. Komurcugil H (2015) Double-band hysteresis current-controlled single-phase shunt active filter for switching frequency mitigation. Int J Electr Power Energy Syst 69:131-140

24. Bhople SU et al (2016) Comparison of various reference current generation techniques for performance analysis of shunt active power filter using Matlab simulation. Int J Curr Eng Technol

25. Chauhan SK, Shah MC, Tiwari RR, Tekwani PN (2013) Analysis, design and digital implementation of a shunt active power filter with different schemes of reference current generation. IET Power Electronics 7(3):627-639

26. Khechiba K, Laid Z, Abdallah K, Anissa K (2018) Comparative analysis on shunt active power filter based $P Q$ control strategy using HCC, SPWM and SVPWM switching signal generation techniques. In: 2018 15th international multi-conference on systems, signals \& devices (SSD). IEEE, pp 936-940

27. Lascu C et al (2007) High performance current controller for selective harmonic compensation in active power filters. IEEE Trans Power Electron 22(5):1826-1835

28. Tarisciotti L et al (2017) Model predictive control for shunt active filters with fixed switching frequency. IEEE Trans Ind Appl 53(1):296-304

29. Shabeer $S$ et al (2016) Shunt hybrid power filter for harmonic reduction to improve power quality using $\mathrm{PI}$ and hysteresis controller. Int J Comput Appl 147(4):7-12

30. Panigrahi R et al (2017) Performance enhancement of shunt active power filter using a Kalman filter-based $\mathrm{H}$ infinity control strategy. IEEE Trans Power Electron 32(4):26222630

31. Hornik T et al (2011) A current-control strategy for voltagesource inverters in microgrids based on repetitive control. IEEE Trans Power Electron 26(3):943-952

32. Badoni M, Singh A, Singh B (2016) Comparative performance of wiener filter and adaptive least mean square-based control for power quality improvement. IEEE Trans Ind Electron 63(5):3028-3037

33. Acuna P et al (2014) Improved active power filter performance for renewable power generation systems. IEEE Trans Power Electron 29(2):687-694

34. Sreeraj ES et al (2014) An active harmonic filter based on onecycle control. IEEE Trans Ind Electron 61(8):3799-3809

35. Swain SD et al (2017) Improvement of power quality using a robust hybrid series active power filter. IEEE Trans Power Electron 32(5):3490-3498

36. Tarisciotti $L$ et al (2017) Model predictive control for shunt active filters with fixed switching frequency. IEEE Trans Ind Appl 53(1):296-304

37. Bandal VS, Madurwar PN (2012) Performance analysis of shunt active power filter using sliding mode control strategies. In: 2012 IEEE 12th international workshop on variable structure systems (VSS)

Publisher's Note Springer Nature remains neutral with regard to jurisdictional claims in published maps and institutional affiliations. 